\title{
KAHVE Laboratory RF Circulator and Transmission Line Project
}

\author{
Hakan Cetinkaya ${ }^{1,2, \text { a) }}$, Aslıhan Çağlar ${ }^{3, \text { b) }}$, Cihan Çiçek ${ }^{1, c)}$, Aydın Özbey, d), Ezgi \\ Sunar ${ }^{1, \text { e) }}$, Görkem Türemen ${ }^{5, f)}$, Hüseyin Yıldız ${ }^{4, g)}$, Alperen Yüncü ${ }^{1, h)}$, Erkcan \\ Özcan ${ }^{1, \text { i) }}$, Gökhan Ünel ${ }^{6, j)}$, and Fatih Yaman ${ }^{3, k}$
}

\author{
${ }^{1}$ Boğaziçi University, 34342 İstanbul, Turkey \\ ${ }^{2}$ Dumlupinar University, 43100 Kütahya, Turkey \\ ${ }^{3}$ İzmir Institute of Technology, 35430 Izmir, Turkey

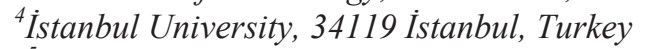 \\ ${ }^{5}$ Ankara University, 06590 Ankara, Turkey \\ ${ }^{6}$ UCI, Irvine, 92697 California, USA \\ ${ }^{a)}$ Corresponding author: hcetinkaya@gmail.com \\ b)caglaraslihan@gmail.com \\ c)cicek154@gmail.com \\ d)ozbeya@istanbul.edu.tr \\ e) sunarezgi@gmail.com \\ f)turemengorkem@gmail.com \\ g)yildizhuseyin@gmail.com \\ h)alperen.yuncu@boun.edu.tr \\ i)erkcan.ozcan@cern.ch \\ ${ }^{j}$ gokhan.unel@cern.ch \\ k) fatihyaman@iyte.edu.tr
}

\begin{abstract}
An $800 \mathrm{MHz}$ RF circulator and transmission line project has recently started at the newly commissioned Kandilli Detector, Accelerator and Instrumentation (KAHVE) Laboratory at the Boğaziçi University. The aims are to design, build and construct an RF circulator and transmission line in Turkey for high power and high frequency applications. The project consists of 8 transmission line elements: $800 \mathrm{MHz}$ RF generator with $60 \mathrm{~kW}$ power (klystron), klystron to waveguide converter, waveguides, $\mathrm{E}$ and $\mathrm{H}$ bends, 3-port circulator and waveguide to coaxial converter to transmit RF power to a pillbox RF cavity. Design studies and details of the ongoing project will be presented.
\end{abstract}

\section{INTRODUCTION}

KAHVE Laboratory has recently been founded at the Bogazici University with the aim of contributing to particle accelerator and detector technologies, which are flourishing only recently in Turkey. The RF circulator and associated transmission line project described here is one of the ongoing projects at the KAHVE Laboratory. It is aimed as a means to transmit high power (at least $50 \mathrm{~kW}$ ) from an RF power supply to targeted devices like accelerator cavities. 
A circulator is one of the most important passive transmission line elements for high power transmission because it protects the RF power source from possible cases of reflected power. It may have 3 or more ports, and is a nonreciprocal device, which means power entering from port 1 goes to port 2, power reflected from port 2 goes to port 3 where for instance a dummy load can be placed to absorb RF energy to be converted in to heat. The non-reciprocity is achieved through the use of a magnetic material, a ferrite placed at center of the circulator that causes a rotation of the RF wave in the presence of an externally applied magnetic field $[1,2]$. The rest of this paper presents a summary of our design studies of our RF system, including the circulator.

\section{DESIGN STUDIES}

This study consists of a classical Y-junction circulator and an RF transmission line which includes power supply to coaxial converter ( $\mathrm{N}$ type to $31 / 8$ " coaxial converter), coaxial to waveguide converter (3 1/8" coaxial to waveguide converter), WR1150 waveguides, E and H bends, waveguide to coaxial converter (waveguide to $31 / 8$ " converter) and finally a pillbox RF cavity into which power will be transmitted. It is also planned to design and produce a pillbox cavity with coupler antenna for simple low power tests before designing the final accelerator cavity. Silicon Carbide (SiC) ceramic will be used as an absorber in the RF dummy load [3]. A $100 \mathrm{~W}, 800( \pm 5)$ $\mathrm{MHz}$ custom-made RF power supply produced in Turkey will be used for the initial tests to understand the related problems and prepare the system for high power tests. After that a $58 \mathrm{~kW}, 800 \mathrm{MHz}$ YK 1198 UHF Power Klystron will be used for high power tests ${ }^{1}$. General schematics of the system are depicted in Fig. 1.

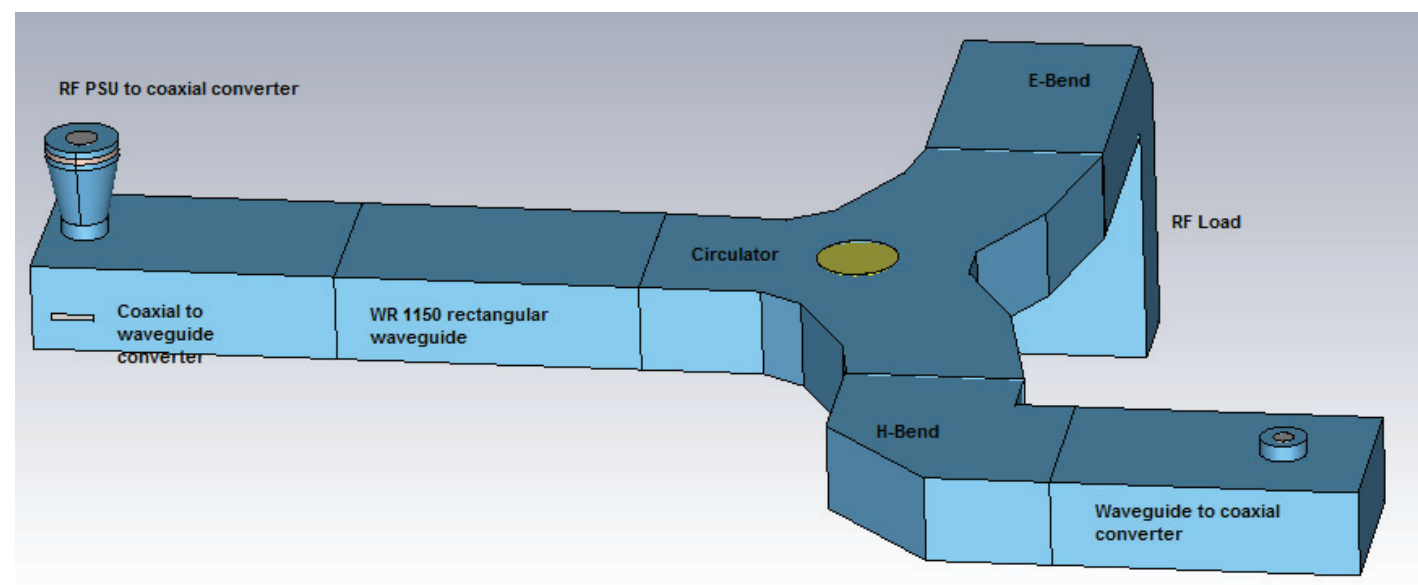

FIGURE 1. General schematics of the design

Design studies excluding the pillbox cavity has been completed. Simulation studies have been performed by using the CST computer software [4]. The simulated S parameters for the current design of the circulator are shown in Fig. 2. Narrow-linewidth calcium-vanadium-doped garnet has been chosen as the ferrite material for low losses. Its saturation magnetization, $4 \pi \mathrm{M}_{\mathrm{s}}$ is $1200 \mathrm{G}$, line width is $10 \mathrm{Oe}$ and Curie temperature is $180^{\circ} \mathrm{C}$.

It is seen from Fig. 2, that $98 \%$ of the power is transmitted from port 1 to port 2 and only $5 \%$ of the power from port 2 is reflected to port 3 . The dimensions of the circulator have been adjusted to take into account the possible effects of mechanical production errors and it has been determined in the simulation studies that such production errors can be compensated by modifying the external magnetic field. Such a field can be obtained with electromagnets and by modifying the current; the field strength can easily be adjusted.

\footnotetext{
${ }^{1}$ Donated from CERN to Turkey.
} 


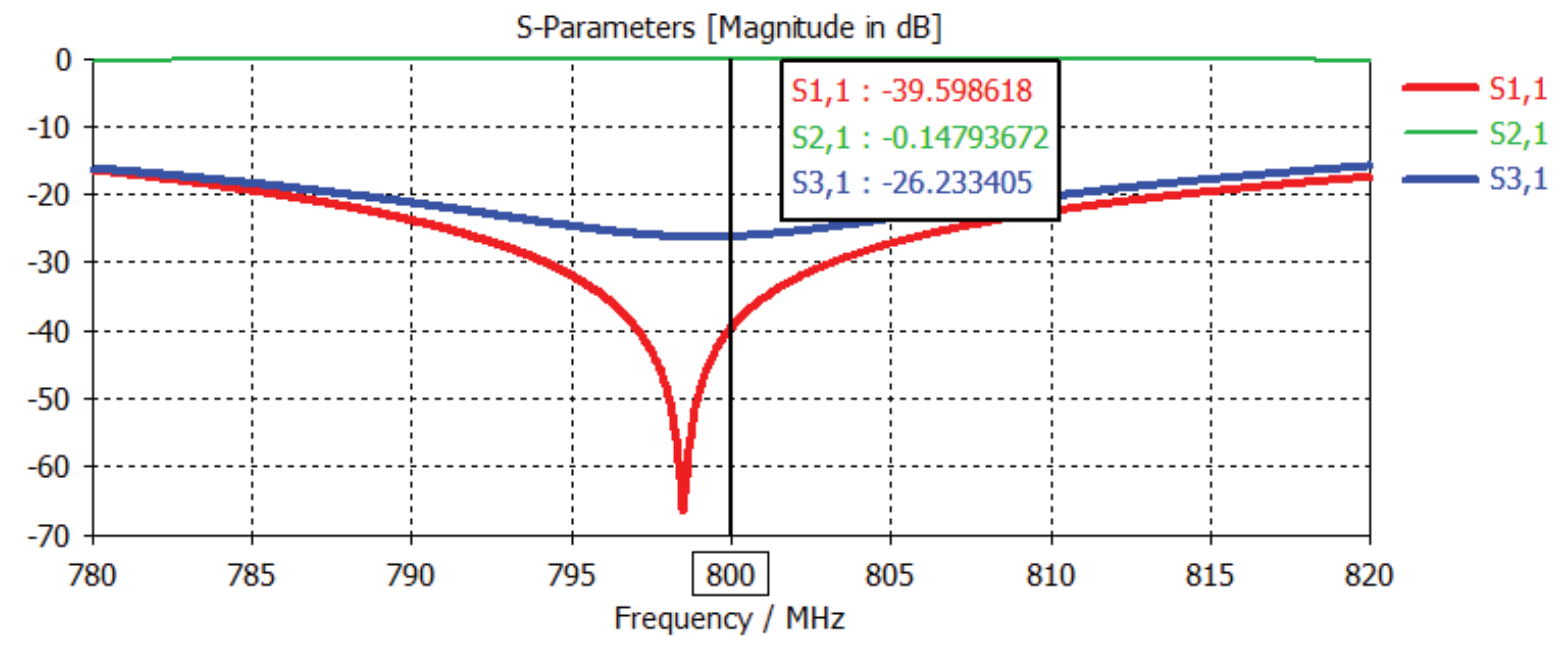

FIGURE 2. Circulator S parameter results obtained from the CST simulations.

Temperature of the ferrite material becomes important in the circulator operations, given that it will loose its magnetic properties above its Curie temperature. Thermal analysis simulations have been performed for $100 \mathrm{~W}$ power for the circulator operation given in Fig. 3. Initial temperature of the system is taken as $25{ }^{\circ} \mathrm{C}$ in the simulations and highest temperature of the system is determined to be $30.64{ }^{\circ} \mathrm{C}$, which is observed around the ferrite region as expected (Fig. 3(b)). Given that the Curie temperature for the chosen ferrite material is $180^{\circ} \mathrm{C}$, it is safe to assume that $100 \mathrm{~W}$ power will have no effect on the circulator operation.

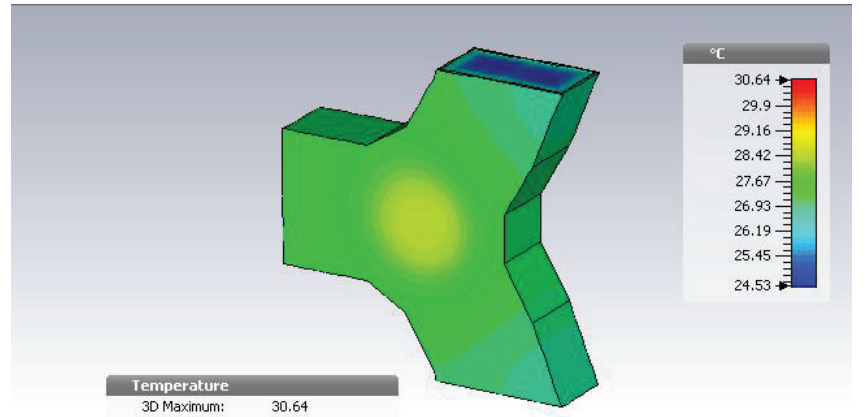

(a)

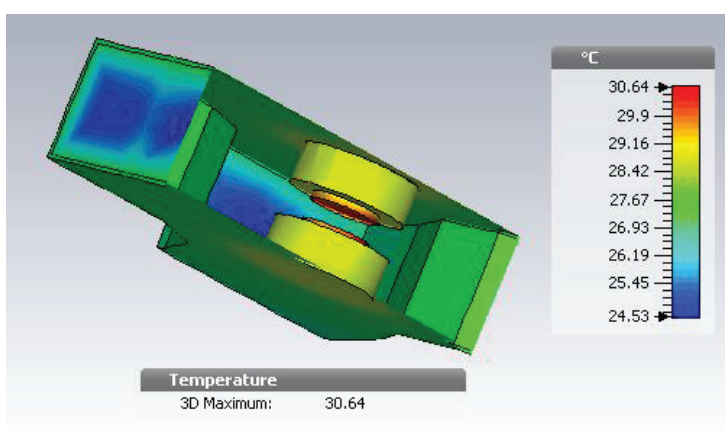

(b)

FIGURE 3. Thermal analysis results obtained using CST simulations.

Simulation studies of the transmission line elements have also been completed. Transmitted and reflected power levels for each transmission line element are listed in Table 1. Simulations for each transmission line element have been computed individually. For each component, it is seen that above $98 \%$ of the power will be transmitted.

TABLE 1. Transmission line elements reflected and transmitted power levels.

\begin{tabular}{|l|l|l|}
\hline Transmission Line Element & Reflected Power (\%) & Transmitted Power (\%) \\
\hline N type to 3 1/8" coaxial converter & 0.1 & 99.9 \\
\hline $31 / 8$ ' coaxial to waveguide converter & 0.1 & 99.9 \\
\hline E bend & 0.12 & 98.8 \\
\hline H bend & 0.18 & 98.2 \\
\hline waveguide to 3 1/8' coaxial converter & 0.15 & 98.5 \\
\hline
\end{tabular}




\section{FUTURE PLANS}

Design studies of an RF Circulator and transmission line have been presented above. Mechanical production and experimental tests are the next steps. Mechanical production has itself been divided into three batches, which are the production of the transmission line elements, the circulator and a pillbox cavity. Mechanical production of the

transmission line elements has started, the testing of these elements will involve both mechanical inspections and S parameter measurements by using a Vector Network Analyzer. Solenoid design and its cooling system design will be performed after the tests of transmission line elements have been completed. Simultaneously, the design of the pillbox cavity will be finalized and its mechanical production will be started. The assembly of the whole system and the trials with $100 \mathrm{~W}$ RF power supply will eventually follow.

\section{ACKNOWLEDGMENTS}

This study is supported by the Scientific and Technological Research Council of Turkey (TUBITAK) under the grant 116E221. The authors are grateful to other members of the Kandilli Algıç, Hızlandırıcı ve Enstrumantasyon Laboratory Team for their inputs and acknowledge the contribution of the Boğaziçi BAP grant 16B03S10 in establishing the infrastructure of the lab. H. Cetinkaya is grateful to the Dumlupinar University Dept. of Physics for accommodating his extended leave and to Bogazici University Dept. of Physics for their hospitality. Part of the work we presented has been run on a trial version of the CST software at the courtesy of Aktif Neser Elektronik Ltd.

\section{REFERENCES}

1. D. K. Linkhart, Microwave Circulator Design, Artech House Microwave Library, 2014.

2. A. G. Fox, S. E. Miller, M. T. Bell, Behavior and Applications of Ferrites in the Microwave Region, Bell System Technical Journal, 34, pp. 5-103, 1955.

3. H. Matsumoto, Y. Iino, C. Fujiwara, Z. Kabeya, T. Onda, Experience on the High-power SiC Microwave Dummy-load Using SiC Absorber, Proceedings of the 1999 Particle Accelerator Conference, New York, pp. 842-844, 1999.

4. CST Microwave Studio Suite User's Manual, 2013. 